\title{
Effects of stepwise dry/wet-aging and freezing on meat quality of beef loins
}

\author{
Yuan H. Brad Kim ${ }^{1 *}$, Brandon Meyers ${ }^{1}$, Hyun-Wook Kim ${ }^{1}$, Andrea M. Liceaga ${ }^{2}$, Ronald P. \\ Lemenager $^{1}$ \\ ${ }^{1}$ Department of Animal Sciences, Purdue University, West Lafayette, IN 47907, USA \\ ${ }^{2}$ Sensory Evaluation Lab., Department of Food Science, Purdue University, West Lafayette, \\ IN 47907, USA
}

\author{
*To whom correspondence should be addressed. Phone +1-765-496-1631; \\ E-mail address: bradkim@ @urdue.edu (Yuan H. Brad Kim)
}

\begin{abstract}
The objective of this study was to evaluate the effects of stepwise dry/wet-aging and freezing method on quality attributes of beef loins. Paired loins (M. Longissimus lumborum) from eight carcasses were assigned to either stepwise dry/wet-aging (carcass dry-aging for 10 days then further wet-aging for 7 days in vacuum bags) or carcass dry-aging only for 17 days. Then, each loin was divided into three sections for freezing (never-frozen, blast or cryogenic freezing). Stepwise dry/wet-aged loin had lower purge/drip loss and shear force than conventionally dry-aged loin $(P<0.05)$, but similar color and sensory characteristics $(P>0.05)$. The cryogenic freezing resulted in a significant decrease in shear force values and a significant improvement in water-holding capacity (WHC). These findings indicate that the stepwise dry/wet-aging coupled with cryogenic freezing could provide beneficial impacts to the local meat industry by providing equivalent quality attributes as conventional dry-aging and improving WHC of frozen/thawed meat, while reducing the time needed for dry-aging.
\end{abstract}

Keywords: beef, wet-aging, carcass dry-aging, cryogenic freezing, water-holding capacity, sensory attributes 


\section{Introduction}

Dry-aging is a traditional process to store whole carcasses or unpackaged primals or subprimals under a controlled environment (e.g. temperature, humidity, and air flow) for a certain period of time (Kim, Kemp, \& Samuelsson, 2016; Savell, 2008). Due to its known positive impacts on palatability attributes (particularly flavor), dry-aging has been typically practiced in local meat processors or small meat purveyors for upscale butcher shops and/or gourmet restaurants (Savell, 2008; Warren \& Kastner, 1992). Although most dry-aging involves beef sub-primals (particularly middle portion), conventional carcass dry-aging (by hanging whole carcass sides in a cooler for 10 to 35 days) still has been practiced in many local meat processors as a value adding process to attract local customers (Jeremiah \& Gibson, 2003; Richardson, Nute, \& Wood, 2008).

However, outcomes of several studies have provided conflicting results showing no detectable dry-aging impacts on palatability components of beef (Dikeman, Obuz, Gök, Akkaya, \& Stroda, 2013; Laster et al., 2008; Smith et al., 2008) despite considerable costs associated with yield loss due to excessive surface drying and additional trimming. Given the fact that dry-aging is an extremely costly and time-consuming process (Savell, 2008), these conflicting results indicate that there remains a need to reassess the efficacy of dry-aging beef carcasses for an extended period of time. Furthermore, many studies found that wet-aging, whereby storing vacuum-packaged primals or sub-primals in a sealed barrier package at refrigeration temperature, could result in equivalent eating quality attributes of beef muscles compared to the dry-aged counterparts (Dikeman et al., 2013; Laster et al., 2008; Parrish, Boles, Rust, \& Olson, 1991; Smith et al., 2008).

While there have been inconsistent results regarding the effects of dry- and wet-aging on meat quality, it would be reasonable to postulate that combining these two aging methods as stepwise dry/wet-aging, by conducting carcass dry-aging first and then continued wet-aging 
beef loins for additional times, could provide equivalent meat quality attributes to beef loins from the conventional carcass dry-aged only counterpart for the same aging period.

In addition to carcass dry-aging, "freezer beef" is one of the most common ways for local processers to merchandise their beef products for regional consumers, as freezing is one of the most effective and efficient methods for food preservation. However, considerable quality deteriorations caused by increased purge/drip loss and/or reduced meat eating attributes have been often associated with the previously frozen meat (Leygonie, Britz, \& Hoffman, 2012; Mateo-Oyague \& Perez-Chabela, 2004). A recent study from Kim, Liesse, Kemp, and Balan (2015) suggested that the quality attributes of frozen/thawed beef loin could be improved by rapid cryogenic freezing, which could decrease the purge/drip release upon thawing by minimizing structural damage to meat from large extracellular ice-crystal formation. Furthermore, Grayson, King, Shackelford, Koohmaraie, and Wheeler (2014) suggested that freezing/thawing and/or aging could improve the tenderness of beef steaks compared to fresh steaks within the same aging period.

Taken together, we hypothesized that the application of rapid cryogenic freezing to stepwise dry/wet-aged beef could substantially improve meat quality attributes of freezer beef by minimizing the freezing-related tissue damage. This would subsequently add more value to locally processed aged/frozen meat products by improving the appearance through less drip (and thus minimizing the loss of soluble nutrients), reducing weight loss, or minimizing adverse freezing/thawing impacts on meat texture, juiciness, and/or flavor. Therefore, the objective of this study was to evaluate the effects of the stepwise dry/wet-aging coupled with rapid cryogenic freezing on the meat quality of frozen/thawed beef loins. Findings from this study may provide potential implications for local meat processors to develop post-harvest aging/freezing strategies that could accelerate processing throughput, while not compromising palatability attributes of aged and/or frozen/thawed beef. 


\section{Materials and Methods}

\subsection{Raw materials and aging process}

A total of eight steers (approximately 16 months of age; Bos taurus crossbred beef steers; A-maturity; average quality grade of low Choice (USDA, 1997)) was slaughtered at the Purdue University Meat Laboratory over four different slaughter days (2 steers/day). By random, one side of each carcass was conventionally dry-aged in a $1{ }^{\circ} \mathrm{C}$ cooler (average relative humidity $78 \%$; air flow, $1.5 \mathrm{~m} / \mathrm{s}$ ) for 17 days by being suspended on the rail as dry-aged only control. The other side of each carcass was assigned for stepwise dry/wet-aging, where each short loin (M. longissimus lumborum) was separated from dry-aged carcasses at 10 days postmortem. Immediately after, the loins were vacuum-packaged and stored for an additional 7 days as wetaging in the same cooler. On day 17 of total aging time after slaughter, the remaining intact loins were removed from the dry-aged carcasses, and the stepwise dry/wet-aged loins were removed from their vacuum packages. Each loin was cut into three equal sections and randomly assigned to three freezing treatments: blast freezing $(\mathrm{BF})$, cryogenic freezing $(\mathrm{CF})$ and a neverfrozen (NF) control, as shown in Fig. 1. Initial pH and weight of all subsamples were measured prior to the freezing treatments. The NF control samples were further processed for quality analyses such as $\mathrm{pH}$, display color, water-holding capacity (purge/thaw, drip and cook loss), shear force, and sensory analyses.

\subsection{Freezing process}

The loin sections assigned to freezing were vacuum-packaged and immediately subjected to the allocated freezing treatments. The loins assigned to BF were placed into a commercial $20{ }^{\circ} \mathrm{C}$ blast freezer. $\mathrm{CF}$ was conducted by placing the vacuum-packaged loin sections in a liquid nitrogen freezing cabinet (CF Cabinet Freezer, RS Cryo Equipment, Inc., Manteno, USA) set 
at $-75{ }^{\circ} \mathrm{C}$ as an operating temperature. Once the internal target temperature of $-20^{\circ} \mathrm{C}$ was reached, the samples were then removed from the CF cabinet freezer and placed in the $-20{ }^{\circ} \mathrm{C}$ blast freezer with the BF samples. The internal temperatures of beef samples as well as freezing ambient temperature were being recorded for both freezing treatments with the use of type T thermocouples (Omega Engineering, Stamford, CT) connected to an OCTEMP2000 data logger (OctTemp2000, MadgeTech, Inc., Warner, NH). All frozen samples were then stored in the same freezer for 1 month until being thawed. The frozen samples were thawed in a $2{ }^{\circ} \mathrm{C}$ cooler for approximately $48 \mathrm{~h}$ to be used for the further quality analyses.

\section{$2.3 \mathrm{pH}$}

The $\mathrm{pH}$ was measured in triplicate by inserting the $\mathrm{pH}$ probe (HI 99163, Hanna Instruments Inc., Hoonsocket, USA) directly into the beef loin sections at three random locations.

\subsection{Display color}

Four steaks (2.5 cm thickness) along with a meat cube (for drip loss) were cut from each loin section. Each steak from the middle portion was used for display color evaluation and the others were used for other quality analyses as described next sections. The steak was placed on a food grade polystyrene tray, wrapped with oxygen-permeable polyvinylchloride film, and placed under simulated display lighting conditions (approximately 1,450 lx, Color temperature $=3,500 \mathrm{~K}$ ) for 7 days at $2.5{ }^{\circ} \mathrm{C}$. On day 1,4 and 7 of display, the surface color characteristics were measured in three random locations on each steak using a Hunter MiniScan EZ colorimeter (Hunter, Reston, VA, USA) calibrated using a standard white and black tile. The setting for the illuminant was D65 source and the observer was standard $10^{\circ}$. The CIE L*, $a^{*}$, and $b^{*}$ values were used to calculate chroma and hue angle (AMSA, 2012). 


\subsection{Water-holding capacity (purge, drip, and cook loss)}

Purge/thaw loss $(\%)$ of beef loins sections was determined by measuring weight differences between an initial weight prior to freezing and the final weight after freezing/thawing (therefore, purge/thaw loss of never frozen control beef loins was not assessed). After the assigned storage period, the loin sections were removed from the vacuum-packaging and all excess surface water was blotted off using a paper towel and the sample was weighed. Drip loss was obtained following a procedure described by Kim et al. (2015). A small piece of each loin section (approximately $35 \mathrm{~g}$ ) was trimmed of any visible fat or connective tissue, weighed and placed in a sealed container and suspended by a hook in nylon netting. After hanging for 48 hours at $2.5^{\circ} \mathrm{C}$, the sample was blotted with paper towel to remove any surface moisture and reweighed to calculate drip loss as a percentage.

For cook loss, one steak (approximately $2.5 \mathrm{~cm}$ thick) from each loin section that was cooked for the shear force measurement was used. The steaks were weighed first, then cooked at $135^{\circ} \mathrm{C}$ on a flat top electric griddle (Farberware, Walter Idde and Co., Bronx, NY). When the core temperature of steak reached at $41{ }^{\circ} \mathrm{C}$, the steak was turned to other side and cooked to an internal temperature of $71{ }^{\circ} \mathrm{C}$. The temperature was monitored by using a digital temperature logger (OctTemp2000, MadgeTech, Inc., Warner, NH) with a thermocouple (T-type, Omega Engineering, Stamford, CT) inserted into the internal center of each sample. Immediately after cooking, the weight of the cooked samples was recorded. The percentage cook loss was calculated using the difference between the initial weight and cooked weight.

\subsection{Shear force}

The cooked steak samples were analyzed for tenderness using the shear force measurement on six cores from each steak. Each core (using a $1.27 \mathrm{~cm}$ diameter hand-held coring device) was obtained parallel to the muscle fiber orientation and sheared using a Warner-Bratzler shear 
attachment on the TA-XT Plus texture analyzer (Stable Micro System Ltd., UK). Data were collected and analyzed from the shear force values to obtain the maximum force required to shear through each sample, and the peak shear force $(\mathrm{kg})$ of six replicates per steak was averaged and recorded.

\subsection{Sensory evaluation}

Sensory evaluation was conducted with a consumer sensory panel (recruited from students, staff, and faculty members; a total of 120 consumer panelists) administered by the Food Science Sensory Evaluation Laboratory at Purdue University. The steak samples from each treatment (2.54 cm thick; two steaks/treatment) were cooked on the electric griddle following the procedure described in the above section for the cook loss and shear force measurement. Once cooked, each steak was cut into cubes $(1.27 \times 1.27 \times 2.54 \mathrm{~cm})$, placed in a plastic cup, which was labelled with pre-assigned, random three-digit-codes, and served to the panelists. Each steak sample was administered to 6 panelists per session (a total of twenty independent sessions) to evaluate the degree of overall liking on a 9-point hedonic scale (where $1=$ dislike extremely, $5=$ neither like nor dislike, and $9=$ like extremely) as well as intensity of flavor, tenderness, and juiciness on a 5-point intensity scale (where $1=$ extremely flavorful, tender or juicy, 3 = neutral, and 5 = extremely not flavorful, tender or juicy). Data were collected using a sensory data collection software (Compusense ${ }^{\circledR}$ 5.0), averaged and analyzed using Statistical Analysis Software (SAS) version 9.1 (SAS Institute, Inc., Cary, NC).

\subsection{Data analysis}

The experimental design was a split-plot, where each carcass served as a block, carcass sides served as the whole plot for the aging treatment (stepwise dry/wet-aging and dry-aging only), and each loin section served as the sub-plot for the freezing treatment (never frozen 
control, BF and CF). A model including the fixed main effects of aging and freezing treatments and the random effect of slaughter day, carcass, carcass side, loin section and their interactions were analyzed by using the mixed procedure of SASC software package $(9.4,2012)$ for ANOVA. For sensory evaluation analysis, the aging and freezing treatments were considered as the fixed effect, and panelists and each session were considered as the random effect in the model. Significant differences in least squares means were separated (F-test, $P<0.05$ ) by using least significant differences analyzed by the PDIFF option in SAS.

\section{Results and discussion}

\subsection{Freezing rate and $\mathrm{pH}$}

A distinct difference was observed in the freezing rate of beef loins assigned to the two different freezing conditions (blast freezing vs. cryogenic freezing), regardless of different aging method (Fig. 2). The CF loins had a substantially faster freezing rate compared to the BF loins, where it took approximately $2 \mathrm{~h}$ for the $\mathrm{CF}$ loins to reach the ultimate internal freezing temperature of $-20^{\circ} \mathrm{C}$, while the $\mathrm{BF}$ loins took more than $15 \mathrm{~h}$ to fall below $-20^{\circ} \mathrm{C}$. In particular, a considerably longer initial characteristic freezing time $(T c)$, which is defined as the elapsed time to decrease from -1 to $-7^{\circ} \mathrm{C}$ where most ice crystal formation (80\%) occurs (Bevilacqua, Zaritzky, \& Calvelo, 1979), was observed in the BF loins compared to the CF counterpart. A similar finding was reported by Kim et al. (2015b), who conducted fast freezing by placing beef loin samples (similar loin sample dimension to the present study) in a calcium chloride immersion tank with an operating temperature set at $-18^{\circ} \mathrm{C}$, and a slow freezing by storing beef samples in a conventional air freezer at $-18^{\circ} \mathrm{C}$. They found that the $T c$ for beef samples assigned to fast freezing (immersion tank) was about $2 \mathrm{~h}$, whereas the $T c$ for the samples assigned to slow freezing (air freezer) was $24 \mathrm{~h}$ (Kim et al., 2015b). This observation indicates that cryogenic freezing using the liquid nitrogen freezing cabinet (operating temperature set at $-75{ }^{\circ} \mathrm{C}$ ) 
in the present study could result in a similar freezing rate of beef loin sections that were frozen by the calcium chloride immersion system. Aging methods (either dry-aging or stepwise dry/wet-aging) prior to freezing did not seem to affect the freezing rate of beef loins (Fig. 2).

The final $\mathrm{pH}$ of beef loins ranged from 5.55 to 5.59 , which was not affected by either aging or freezing method (Table $1 ; P>0.05$ ). Similarly, previous studies reported that postmortem aging and/or freezing had little or no impact on $\mathrm{pH}$ of beef, regardless of aging method and/or aging period (Ahnström et al., 2006; Degeer et al., 2009; Kim et al., 2015; Li, Babol, Wallby, Lundström, 2013; Parrish et al., 1991).

\subsection{Color stability}

Effects of stepwise dry/wet-aging and freezing method on color stability of beef loins during 7 days of retail display are shown in Fig. 3. There were no significant interactions between stepwise dry/wet-aging and freezing method on any color attributes of beef loins $(P>0.05$; Fig. 3).

Stepwise dry/wet-aging resulted in similar color characteristics and color stability of beef loins compared to the dry-aged counterparts $(P>0.05)$. Limited information is available regarding the effects of carcass dry-aging on color attributes of beef muscles. There are, however, a few published studies determining the effects of beef sub-primal dry-aging (not conventional carcass dry-aging) on meat color attributes, where most studies found no differences in color between dry-aged and wet-aged beef loins (Brugiapaglia, Destefanis, \& Vincenti, 2015; Dikeman et al., 2013; Kim et al., 2015). Kim et al. (2015) reported that dry-aging did not result in any substantial adverse impacts on meat color, once the initial trimming process of dry-aged

surface was completed. The result of our current study also suggests that stepwise dry/wetaging would not attribute to any negative influence on color and color stability of beef loins. 
Different freezing rates did not affect color attributes and color stability of beef loins, irrespective of aging method. This observation was in agreement with the results from the similar study by Kim et al. (2015), where they found that freezing rate created by different freezing methods did not affect the extent/rate of surface myoglobin oxygenation and redox stability of thawed beef loins during retail display (Kim et al., 2015).

In the present study, however, freezing/thawing itself affected color attributes of beef loins compared to the never frozen beef loins $(P<0.05)$. Overall, the steaks from never frozen loins (NF control) showed higher $\mathrm{L}^{*}$ and $\mathrm{a}^{*}$, and lower $\mathrm{b}^{*}$ and hue angle values compared to the steaks from the frozen/thawed (BF and CF) loins $(P<0.05$; Fig. 3). A greater extent of discoloration as shown by lower $a^{*}$ (redness) and higher hue angle values of the steaks from the frozen/thawed loins compared to the NF steaks was observed at day 4 and 7 of display. This observation indicates that steak samples from frozen/thawed beef loins were more susceptible to myoglobin oxidation than never-frozen beef loins. It is well recognized that during freezing, intra- and/or extra-cellular ice crystal formation occurs within the muscle tissue, which in turn damages muscle cells and tissue structure upon thawing, resulting in an alteration of optical properties affecting meat color (Mateo-Oyague \& Perez-Chabela, 2004). Furthermore, several studies reported that more rapid discoloration of frozen/thawed meat compared to never-frozen meat could be attributed to myoglobin denaturation and subsequent accumulation of metmyoglobin, as well as loss of metmyoglobin reducing ability (Jeong, Kim, Yang, \& Joo, 2011; Kim, Frandsen, \& Rosenvold, 2011; Kim et al., 2015; Kim, Luc, \& Rosenvold, 2013; Leygonie et al., 2012).

\subsection{Water Holding Capacity (WHC)}

There was no significant interaction between aging method and freezing type in WHC. Therefore, the main effects of aging method and freezing type were determined independently. 
For purge/thaw loss of beef loins, no significant impact of aging method prior to freezing was found, where stepwise dry/wet-aged beef loins and dry-aged beef loins had similar purge/thaw loss $(2.9 \%$ and $2.8 \%$, respectively; Table 1$)$. Further, cook loss was not affected by aging method $(P>0.05$; Table 1). However, dry-aged beef loins exhibited significantly higher drip loss $(5.0 \%)$ compared to stepwise dry/wet-aged beef loins $(2.8 \%)$. In a subsequent combined value of purge and drip losses, stepwise dry/wet-aged beef loins had a lower amount of water loss than dry-aged beef loins $(P<0.05$; Table 1$)$.

It was uncertain why stepwise dry/wet-aging resulted in a decrease in drip loss of the loins compared to dry-aged beef counterparts, particularly when this trend was not observed in purge/thaw loss and cook loss, as described above. Several biochemical changes including proteolysis, activation of protease-inhibitor, and/or protein oxidation during postmortem aging could affect the degradation of myofibrillar proteins, which is associated with WHC as well as tenderness (Huff-Lonergan \& Lonergan, 2005). In particular, adverse impacts of protein oxidation on WHC and/or eating quality attributes of fresh meat have been well reported (Kim, Huff-Lonergan, Sebranek, \& Lonergan, 2010; Kim, Bødker, \& Rosenvold, 2012; Lund, Lametsch, Hviid, Jensen, \& Skibsted, 2007; Zakrys-Waliwander, O’Sullivan, O’Neill, \& Kerry, 2012). Possibly, the conventional carcass dry-aging may result in more protein oxidation of beef loins (since no packaging materials are used) compared to the loins from the stepwise dry/wet-aging, and thus likely attribute to an increase in drip loss of the loins. Further study is warranted to understand the impact of aging method on protein oxidation and subsequent WHC of beef muscles.

When it comes to freezing effect on WHC, CF resulted in lower purge/thaw loss of beef loins $(2.03 \%)$ than $\mathrm{BF}(3.67 \%, P<0.0001$; Table 1$)$, irrespective of aging method. A decrease in purge loss of frozen/thawed meat through fast freezing has been well documented. The physical cell damage and distortion and/or rupture of muscle fiber associated with freezing can be 
diminished by accelerated freezing, since the smaller size and evenly distributed ice crystal formation within muscle fibers can be induced by fast freezing compared to slow freezing (Bevilacqua et al., 1979; Bevilacqua \& Zaritzky, 1980; Mateo-Oyague \& Perez-Chabela, 2004). Hergenreder et al. (2013) reported that purge loss of three subprimals (M. longissimus thoracis, lumborum, and gluteus medius) was decreased when assigned to fast freezing. Also, Kim et al. (2015) reported that fast freezing (using calcium chloride immersion tank) resulted in lower purge/thaw loss of beef loins compared to slow freezing (conventional air freezing).

No significant difference in drip loss between treatments was observed due to freezing method, although there was a trend of higher drip loss of frozen beef loins than never frozen beef loins $(P=0.08)$. Similarly, no significant freezing method impact on cook loss of beef loins was found $(P>0.05$; Table 1$)$, which is in agreement with other similar freezing/thawing studies (Kim et al., 2015a; Muela, Sañudo, Campo, Medel, \& Beltrán, 2010; Vieira, Diaz, Martínez, \& García-Cachán, 2009). Taken together, this observation indicates that the reduced purge/thaw loss would be the most distinct/apparent result affected by fast freezing in terms of WHC compared to drip and cook loss.

\subsection{Shear force values}

There was no significant interaction between aging and freezing methods on shear force values of beef loins, but significant main effects were found $(P<0.05$; Table 1$)$. The beef loins assigned to stepwise dry/wet-aging had lower shear force values $(2.66 \mathrm{~kg})$ compared to the loins assigned to the conventional carcass dry-aging $(2.94 \mathrm{~kg}, P<0.05)$, irrespective of freezing method. In a hypothetical interpretation, this result would indicate that beef loins that were assigned to the conventional carcass dry-aging for 10 days and then continued vacuum wetaging for 7 days would have lower toughness (based on shear force assessment) compared to the loins assigned to carcass dry-aging only for 17 days. 
This result is somewhat contrary to the findings from Jeremiah and Gibson (2003), where they found that whole carcass dry-aging resulted in significantly lower shear force values of beef loins (4.36 kg) compared to the wet-aged beef (boneless) loins (4.58). However, it should be also noted that the observed differences in shear force values between different aging methods for the current study and the study from Jeremiah and Gibson were relatively small (less than $0.3 \mathrm{~kg}$ ), and thus would not be practically meaningful to influence actual beef tenderness. More detailed discussion regarding the sensory evaluation results including tenderness will be followed in the next section.

Freezing/thawing resulted in lower shear force values of beef loins compared to the never frozen counterparts $(P<0.05)$. No significant freezing rate impact on shear force was found, which was in agreement with recent findings from the similar aged/frozen beef study (Yuan $\mathrm{H}$. Brad Kim et al., 2015). A decrease in shear force values through freezing/thawing has been reported by several studies (Crouse \& Koohmaraie, 1990; Grayson et al., 2014; Lagerstedt et al., 2008; Shanks et al., 2002; Wheeler et al., 1992) and can likely be attributed to the physical destruction of muscle tissue and structural integrity by ice crystals (Petrović, Grujić, \& Petrović, 1993). However, there have been some discrepancies between studies in that whether the reduction of shear force values through freezing/thawing would be translated into improvement in tenderness determined by consumer evaluations. Furthermore, the observed difference in shear force values between the frozen/thawed and never frozen controls (less than $0.43 \mathrm{~kg}$ ) would not be sufficiently high enough to impact meat tenderness of beef loins at the consumer level. In fact, the shear force values of all beef loin samples in the present study (less than or equal to $3 \mathrm{~kg}$ ) should be considered in the tender category (Destefanis, Brugiapaglia, Barge, \& Dal Molin, 2008).

\subsection{Sensory characteristics}


There were no significant interactions between stepwise dry/wet-aging and freezing method on sensory characteristics (consumer liking and attribute intensities). Furthermore, neither stepwise dry/wet-aging nor different freezing methods affected any parameters $(P>0.05$; Table 2). These findings indicate that stepwise dry/wet-aging would result in equivalent eating quality attributes of beef loins as to the beef loins from conventionally dry-aged carcasses.

While there has been limited research on determining the effect of carcass dry-aging on meat quality attributes in comparison to other aging methods, a few studies reported contradictory results. Richardson, Nute, and Wood (2008) found that carcass dry-aging resulted in better eating quality characteristics in terms of tenderness and juiciness compared to the wet-aged beef samples from the same carcasses $(P<0.05)$. However, in this study, a trained taste panel did not find the difference in flavor between carcass dry-aged and wet-aged beef loins $(P>$ 0.05). In contrast, Jeremiah and Gibson (2003) reported that wet-aged beef loins had significantly higher eating quality attributes, such as overall tenderness, juiciness, flavor, and overall palatability, compared to the loins from conventionally dry-aged beef carcasses. The cause for this disparity in palatability attributes affected by different aging methods is largely unknown.

In fact, similar inconsistent results have been also reported in 'sub-primal' dry-aging studies. In general, it has been known that dry-aging (of sub-primals) enhances the palatability attributes of meat, especially tenderness and flavor, giving more brown-roasted beefy flavor compared to the wet-aged (in vacuum packaging) counterpart (Warren \& Kastner, 1992). In addition to flavor, a significant improvement in juiciness by dry-aging has been also reported (Campbell, Hunt, Levis, \& Chambers, 2001; Kim et al., 2016).

However, several other studies found no significant dry-aging impacts on palatability components of beef (Dikeman et al., 2013; Laster et al., 2008; Smith et al., 2008) despite considerable cost associated with yield loss due to excessive surface drying and additional trimming. Kim et al. (2016) postulated that the primary reason for these conflicting results would be likely 
due to the inconsistent, or a lack of controlled processing conditions (e.g. temperature, humidity and/or air-flow) applied for dry-aging among different studies. Irrespective of the inconsistent results from studies, the findings from the current study suggest that combining carcass dry-aging with continued wet-aging would result in similar palatability attributes of beef loins compared to the carcass dry-aged only counterpart for the same period of times.

In the present study, the consumer panel found no difference in eating quality attributes between frozen/thawed beef and never frozen (fresh only) beef loins. This would be likely resulted from the positive effect of aging beef prior to freezing. Several studies reported that eating quality differences between fresh and frozen/thawed meat could be reduced by allowing proper/sufficient aging periods prior to freezing (Choe, Stuart, \& Kim, 2016; Farouk, Wiklund, Stuart, \& Dobbie, 2009; Kim et al., 2015). Furthermore, in the current study, no impact of freezing rate on sensory attributes was found, which was in agreement with the study from Hergenreder et al. (2013) who reported that both freezing and thawing rates had no influence on sensory properties of aged beef muscles compared to never-frozen fresh meat.

\section{Conclusion}

The data from this study indicate that stepwise dry/wet-aging resulted in an improvement in WHC (shown by less drip loss and purge + drip loss) and a decrease in shear force values of beef samples compared to the conventional carcass dry-aged loin. Further, the cryogenic freezing resulted in a significant decrease in shear force values and a significant improvement in water-holding capacity in terms of purge and drip loss of frozen/thawed meat.

These findings suggest that the stepwise dry/wet-aging could potentially provide beneficial impacts to local/small meat processors, who have limited cooler capacity, as the carcass chilling time in the cooler can be substantially reduced by the stepwise dry/wet aging. Conse- 
quently, it would allow rapid turnaround of beef sub-primal processing, resulting in more saleable yield through shorter hanging time (less moisture loss) and possibly lower energy/operating costs compared to the conventional carcass dry-aging for an extended period of time. Moreover, rapid cryogenic freezing can substantially improve meat quality attributes of freezer beef by providing equivalent quality attributes and improved water-holding capacity of aged/frozen/thawed meat.

Further research is warranted to identifying optimal combinations of carcass dry-aging/wet-aging times that would not only improve efficiency of stepwise dry/wet-aging on meat quality attributes, but also maximize economic benefits by reducing costs associated with the aging/freezing process.

\section{Acknowledgements}

This work was supported by the USDA National Institute of Food and Agriculture, HacthMultistate project 1006773 . This work was also funded in part by the Indiana Beef Council. The authors would like to thank Ms. Angela Albright in the Purdue University Food Sensory Laboratory for assisting the sensory evaluations, and the RS Cryo Equipment Company for providing the liquid nitrogen freezing unit. Appreciation is extended to the support of the Purdue Meat Laboratory staff and Meat Science and Muscle Biology Lab members for the successful completion of the sample and data collection. 


\section{References}

Ahnström, M. L., Seyfert, M., Hunt, M. C., \& Johnson, D. E. (2006). Dry aging of beef in a bag highly permeable to water vapour. Meat Science, 73, 674-679.

AMSA. (2012). Guidelines for the measurement of meat color. Champaign, Illinois, USA: American Meat Science Association.

Bevilacqua, A., Zaritzky, N. E., \& Calvelo, A. (1979). Histological measurements of ice in frozen beef. International Journal of Food Science \& Technology, 14, 237-251.

Bevilacqua, A. E. \& Zaritzky, N. E. (1980). Ice morphology in frozen beef. International Journal of Food Science \& Technology, 15, 589-597.

Brugiapaglia, A., Destefanis, G., \& Vincenti, L. (2015). Extended dry ageing time effect on water holding capacity and colour of piemontese cull cow beef. Paper presented at the 61st International Congress of Meat Science and Technology, Clermont-Ferrand, France.

Campbell, R. E., Hunt, M. C., Levis, P., \& Chambers, E. (2001). Dry-aging effects on palatability of beef longissimus muscle. Journal of Food Science, 66, 196-199.

Choe, J. H., Stuart, A., \& Kim, Y. H. B. (2016). Effect of different aging temperatures prior to freezing on meat quality attributes of frozen/thawed lamb loins. Meat Science, 116, $158-164$.

Crouse, J. D. \& Koohmaraie, M. (1990). Effect of freezing of beef on subsequent postmortem aging and shear force. Journal of Food Science, 55, 573-574.

DeGeer, S. L., Hunt, M. C., Bratcher, C. L., Crozier-Dodson, B. A., Johnson, D. E., \& Stika, J. F. (2009). Effects of dry aging of bone-in and boneless trip loins using two aging processes for two aging times. Meat Science, 83, 768-774.

Destefanis, G., Brugiapaglia, A., Barge, M. T., \& Dal Molin, E. (2008). Relationship between beef consumer tenderness perception and Warner-Bratzler shear force. Meat Science, $78,153-156$.

Dikeman, M. E., Obuz, E., Gök, V., Akkaya, L., \& Stroda, S. (2013). Effects of dry, vacuum, and special bag aging; USDA quality grade; and end-point temperature on yields and eating quality of beef Longissimus lumborum steaks. Meat Science, 94, 228-233.

Grayson, A. L., King, D. A., Shackelford, S. D., Koohmaraie, M., \& Wheeler, T. L. (2014). Freezing and thawing or freezing, thawing, and aging effects on beef tenderness. Journal of Animal Science, 92, 2735-2740. 
Farouk, M., Wiklund, E., Stuart, A., \& Dobbie, P. (2009). Ageing prior to freezing improves waterholding capacity in beef and venison. Paper presented at the Proceedings of the 55th International Congress of Meat Science and Technology., Copenhagen, Denmark.

Hergenreder, J. E., Hosch, J. J., Varnold, K. A., Haack, A. L., Senaratne, L., Pokharel, S., Beauchamp, C., Lobaugh, B., \& Calkins, C. R. (2013). The effects of freezing and thawing rates on tenderness, sensory quality, and retail, display of beef subprimals. Journal of Animal Science, 91, 483-490.

Huff-Lonergan, E. \& Lonergan, S. M. (2005). Mechanisms of water-holding capacity of meat: The role of postmortem biochemical and structural changes. Meat Science, 71, 194204.

Jeong, J. Y., Kim, G. D., Yang, H. S., \& Joo, S. T. (2011). Effect of freeze-thaw cycles on physicochemical properties and color stability of beef semimembranosus muscle. Food Research International, 44, 3222-3228.

Jeremiah, L. E. \& Gibson, L. L. (2003). The effects of postmortem product handling and aging time on beef palatability. Food Research International, 36, 929-941.

Kim, Y. H., Huff-Lonergan, E., Sebranek, J. G., \& Lonergan, S. M. (2010). High-oxygen modified atmosphere packaging system induces lipid and myoglobin oxidation and protein polymerization. Meat Science, 85, 759-767.

Kim, Y. H. B., Bødker, S., \& Rosenvold, K. (2012). Influence of lamb age and high-oxygen modified atmosphere packaging on protein polymerization of long-term aged lamb loins. Food Chemistry, 135, 122-126.

Kim, Y. H. B., Frandsen, M., \& Rosenvold, K. (2011). Effect of ageing prior to freezing on colour stability of ovine longissimus muscle. Meat Science, 88, 332-337.

Kim, Y. H. B., Kemp, R., \& Samuelsson, L. M. (2016). Effects of dry-aging on meat quality attributes and metabolite profiles of beef loins. Meat Science, 111, 168-176.

Kim, Y. H. B., Liesse, C., Kemp, R., \& Balan, P. (2015). Evaluation of combined effects of ageing period and freezing rate on quality attributes of beef loins. Meat Science, 110, $40-45$.

Kim, Y. H. B., Luc, G., \& Rosenvold, K. (2013). Pre rigor processing, ageing and freezing on tenderness and colour stability of lamb loins. Meat Science, 95, 412-418.

Lagerstedt, Ã., Enfält, L., Johansson, L., \& Lundström, K. (2008). Effect of freezing on sensory quality, shear force and water loss in beef M. longissimus dorsi. Meat Science, 80, $457-$ 461. 
Laster, M. A., Smith, R. D., Nicholson, K. L., Nicholson, J. D. W., Miller, R. K., Griffin, D. B., Harris, K. B., \& Savell, J. W. (2008). Dry versus wet aging of beef: Retail cutting yields and consumer sensory attribute evaluations of steaks from ribeyes, strip loins, and top sirloins from two quality grade groups. Meat Science, 80, 795-804.

Leygonie, C., Britz, T. J., \& Hoffman, L. C. (2012). Impact of freezing and thawing on the quality of meat: Review. Meat Science, 91, 93-98.

Li, X., Babol, J., Wallby, A., \& Lundström, K. (2013). Meat quality, microbiological status and consumer preference of beef gluteus medius aged in a dry ageing bag or vacuum. Meat Science, 95, 229-234.

Lund, M. N., Lametsch, R., Hviid, M. S., Jensen, O. N., \& Skibsted, L. H. (2007). High-oxygen packaging atmosphere influences protein oxidation and tenderness of porcine longissimus dorsi during chill storage. Meat Science, 77, 295-303.

Mateo-Oyague, J., \& Perez-Chabela, M. L. (2004). Frozen Meat Handbook of Frozen Foods: CRC Press.

Muela, E., Sañudo, C., Campo, M. M., Medel, I., \& Beltrán, J. A. (2010). Effect of freezing method and frozen storage duration on instrumental quality of lamb throughout display. Meat Science, 84, 662-669.

Parrish, F. C., Boles, J. A., Rust, R. E., \& Olson, D. G. (1991). Dry and wet aging effects on palatability attributes of beef loin and rib steaks from three quality grades. Journal of Food Science, 56, 601-603.

Petrović, L., Grujić, R., \& Petrović, M. (1993). Definition of the optimal freezing rate-2. Investigation of the physico-chemical properties of beef M. longissimus dorsi frozen at different freezing rates. Meat Science, 33, 319-331.

Richardson, R. I., Nute, G. R., \& Wood, J. D. (2008). Effect of wet vs dry ageing on eating quality of beef from traditional breeds. Paper presented at the 54th International Conference of Meat Science and Technology CapeTown, South Africa.

Savell, J. W. (2008). Dry-aging of beef. Executive summary (pp. 1-16). Centennial, CO: National Cattlemen's Beef Association.

Shanks, B. C., Wulf, D. M., \& Maddock, R. J. (2002). Technical note: The effect of freezing on Warner-Bratzler shear force values of beef longissimus steaks across several postmortem aging periods. Journal of Animal Science, 80, 2122-2125.

Smith, R. D., Nicholson, K. L., Nicholson, J. D. W., Harris, K. B., Miller, R. K., Griffin, D. B., $\&$ Savell, J. W. (2008). Dry versus wet aging of beef: Retail cutting yields and consumer 
palatability evaluations of steaks from US Choice and US Select short loins. Meat Science, 79, 631-639.

USDA. (1997). Official United States standards for grades of carcass beef.

Vieira, C., Diaz, M. T., Martínez, B., \& García-Cachán, M. D. (2009). Effect of frozen storage conditions (temperature and length of storage) on microbiological and sensory quality of rustic crossbred beef at different states of ageing. Meat Science, 83, 398-404.

Warren, K. E. \& Kastner, C. L. (1992). A comparison of dry-aged and vacuum-aged beef strip loins. Journal of Muscle Foods, 3, 151-157.

Wheeler, T. L., Crouse, J. D., \& Koohmaraie, M. (1992). The effect of postmortem time of injection and freezing on the effectiveness of calcium chloride for improving beef tenderness. Journal of Animal Science, 70, 3451-3457.

Zakrys-Waliwander, P. I., O’Sullivan, M. G., O’Neill, E. E., \& Kerry, J. P. (2012). The effects of high oxygen modified atmosphere packaging on protein oxidation of bovine $\mathrm{M}$. longissimus dorsi muscle during chilled storage. Food Chemistry, 131, 527-532. 
Table 1. Effect of stepwise dry/wet-aging and freezing method on $\mathrm{pH}$ and water-holding capacity (WHC, \%), and shear force $(\mathrm{kg})$ of beef loins

\begin{tabular}{lllllll}
\hline Treatments & $\mathrm{pH}$ & $\begin{array}{l}\text { Purge/thaw } \\
\text { loss }\end{array}$ & Drip loss & Cook loss & $\begin{array}{l}\text { Purge }+ \\
\text { Drip loss }\end{array}$ & $\begin{array}{l}\text { Shear } \\
\text { force }\end{array}$ \\
\hline $\begin{array}{l}\text { Aging effect } \\
\text { Dry-aging }\end{array}$ & 5.56 & 2.78 & $5.00 \mathrm{a}$ & 25.04 & $8.37 \mathrm{a}$ & $2.94 \mathrm{a}$ \\
$\begin{array}{l}\text { Stepwise ag- } \\
\text { ing }\end{array}$ & 5.59 & 2.92 & $2.75 \mathrm{~b}$ & 25.74 & $5.97 \mathrm{~b}$ & $2.66 \mathrm{~b}$ \\
$\mathrm{SEM}^{2}$ & 0.02 & 0.24 & 0.55 & 0.92 & 0.55 & 0.12 \\
$\begin{array}{l}P \text { value } \\
\text { Freezing effect }\end{array}$ & 0.1902 & 0.5542 & 0.0003 & 0.4500 & 0.0003 & 0.0194 \\
$\begin{array}{l}\text { Never-frozen } \\
\text { Blast freezing }\end{array}$ & 5.55 & - & & & & \\
$\begin{array}{l}\text { Cryogenic } \\
\text { freezing }\end{array}$ & 5.59 & $3.67 \mathrm{a}$ & 4.29 & 26.1 & $7.96 \mathrm{a}$ & $2.70 \mathrm{~b}$ \\
$\begin{array}{l}\text { SEM } \\
P \text { value }\end{array}$ & 0.02 & 0.24 & 0.68 & 1.13 & 0.55 & 0.15 \\
\hline
\end{tabular}

${ }^{1}$ Dry aging, carcass dry-aging for 17 days; stepwise dry/wet-aging, carcass dry-aging for 10 days and further wet-aging for 7 days.

${ }^{2}$ SEM: standard error of the mean.

a,b Treatment means with different letters within each aging or freezing effect are different $(P$ $<0.05)$. 
Table 2. Effect of stepwise dry/wet-aging and freezing method on sensory properties of beef loins

\begin{tabular}{lllll}
\hline Treatments & Overall liking $^{1}$ & Flavor & Tenderness & Juiciness \\
\hline Aging effect $^{2}$ & & & & \\
Dry aging & 6.94 & 3.46 & 2.32 & 2.56 \\
Stepwise aging & 7.05 & 3.53 & 2.19 & 2.50 \\
SEM $^{3}$ & 0.10 & 0.08 & 0.11 & 0.15 \\
$P$ value & 0.3196 & 0.4307 & 0.2531 & 0.7055 \\
Freezing effect & & & & \\
Never-frozen & 7.01 & 3.39 & 2.19 & 2.45 \\
Blast freezing & 7.04 & 3.54 & 2.20 & 2.47 \\
Cryogenic freezing & 6.94 & 3.55 & 2.38 & 2.67 \\
SEM & 0.12 & 0.09 & 0.14 & 0.16 \\
$P$ value & 0.7435 & 0.1397 & 0.3210 & 0.3262 \\
\hline
\end{tabular}

${ }^{1}$ Overall liking $(1=$ dislike extremely and $9=$ like extremely), flavor $(1=$ extremely flavorful and $9=$ extremely not flavorful $)$, tenderness $(1=$ extremely tender and $9=$ extremely not tender), and juiciness $(1=$ extremely juicy and $9=$ extremely not juicy).

${ }^{2}$ Dry aging, whole carcass dry-aging for 17 days; stepwise aging, whole carcass dry-aging for 10 days and further wet-aging for 7 days.

${ }^{3}$ SEM: standard error of the mean. 
(a) Aging procedure

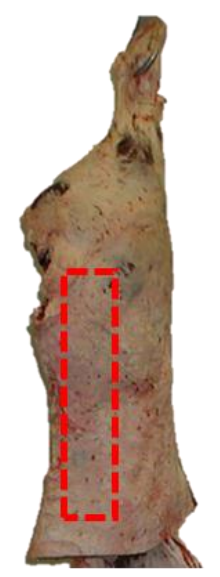

Side I: carcass dry-aging Side II: stepwise dry/wet-aging (17 days)

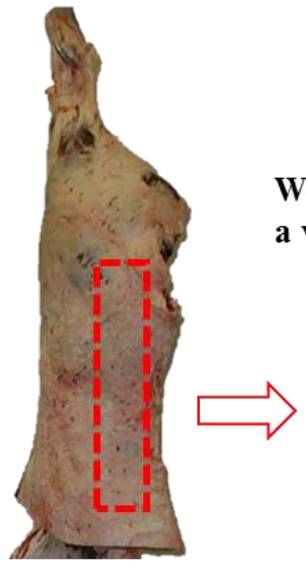
(carcass dry-aging for 10 days and wet-aging for 7 days) (b) Freezing procedure

Three loin sections from each side of carcasses were randomly assigned into $\mathrm{NF}, \mathrm{BF}$ and $\mathrm{CF}$.
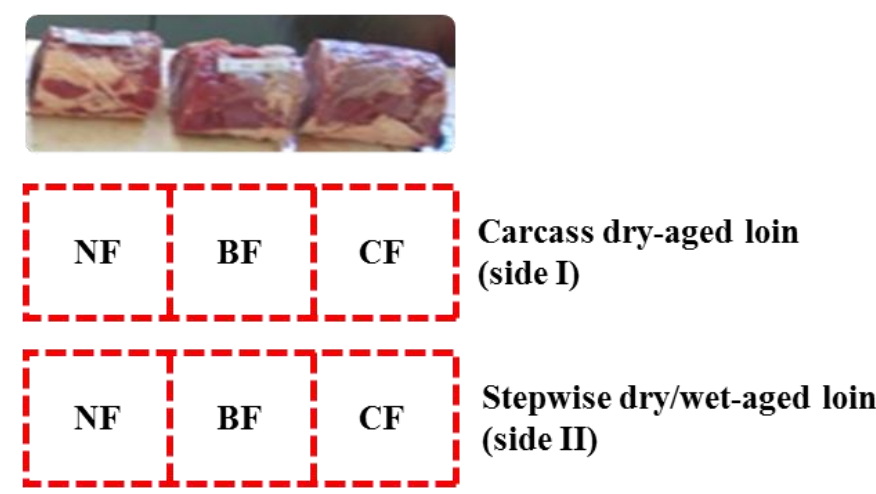

Fig. 1. Schematic figures illustrating carcass dry-aging verse stepwise dry/wet-aging (a) and the treatment random allocation $(\mathrm{NF}$, never-frozen control; $\mathrm{BF}$, blast-frozen; $\mathrm{CF}$, cryogenic frozen) (b). 


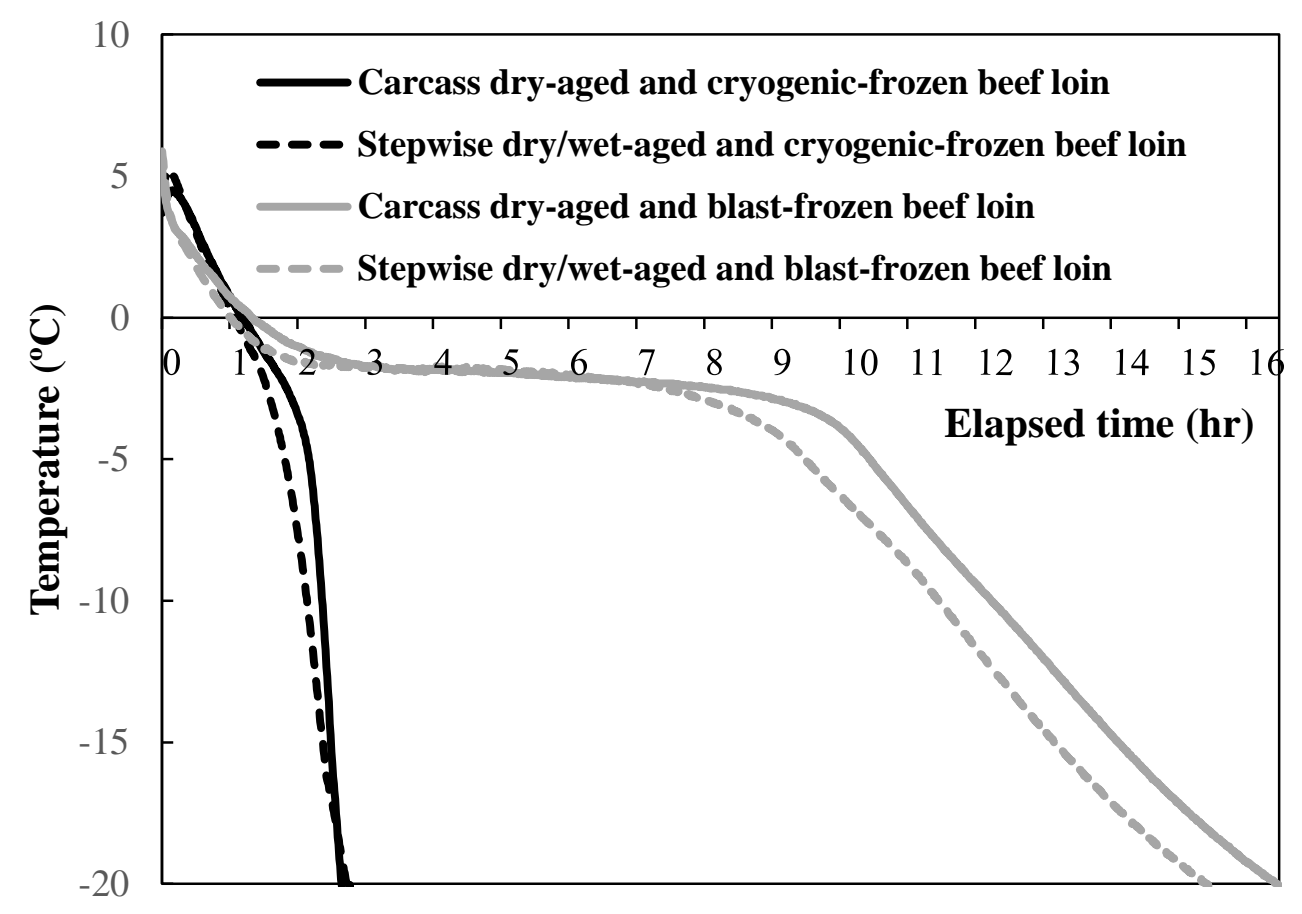

Fig. 2. Time-temperature profiles of carcass dry-aged and stepwise dry/wet-aged beef loins assigned to either blast-frozen or cryogenic-frozen treatments. The blast-frozen samples were placed in a commercial $-20^{\circ} \mathrm{C}$ blast freezer, while the cryogenic-frozen samples were placed in a liquid nitrogen freezing cabinet. 
(a) Aging effect on lightness (SEM: 1.26)

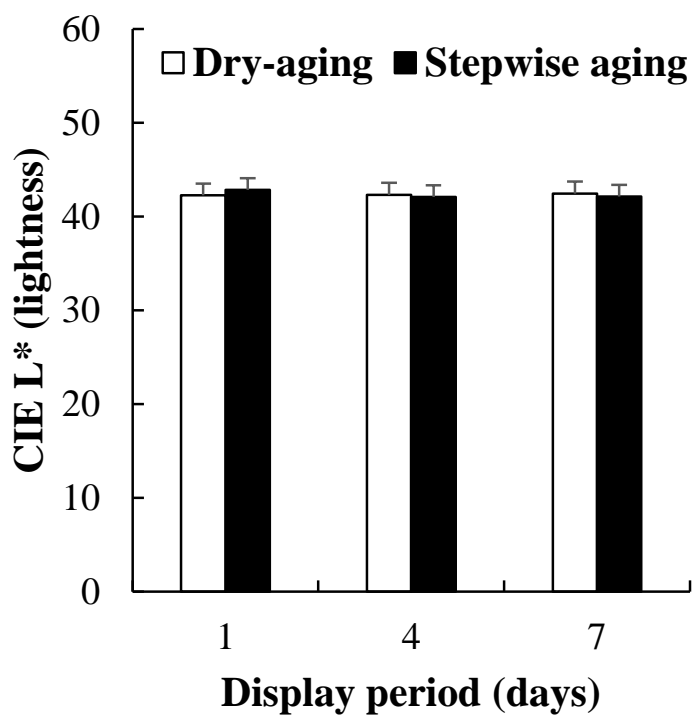

(c) Aging effect on redness (SEM: 1.38)

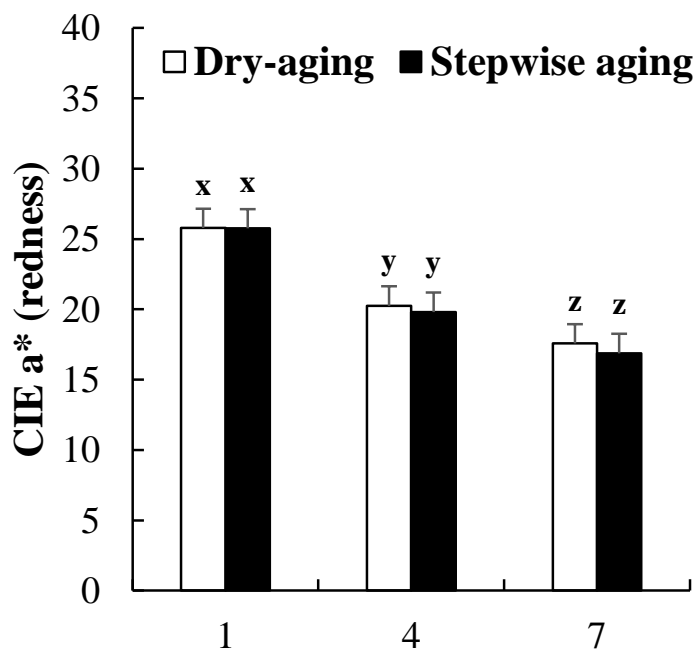

Display period (days) (b) Freezing effect on lightness (SEM: 0.71)

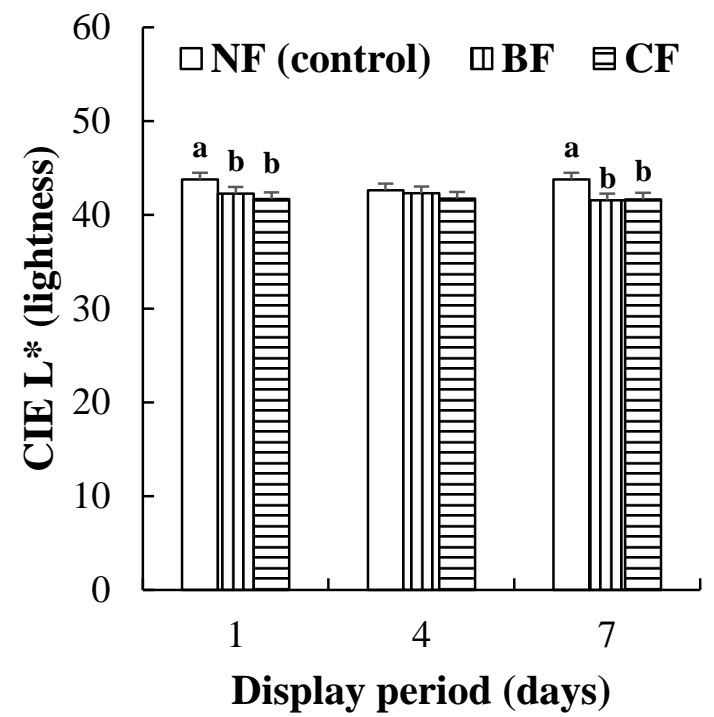

(d) Freezing effect on redness (SEM: 1.44)

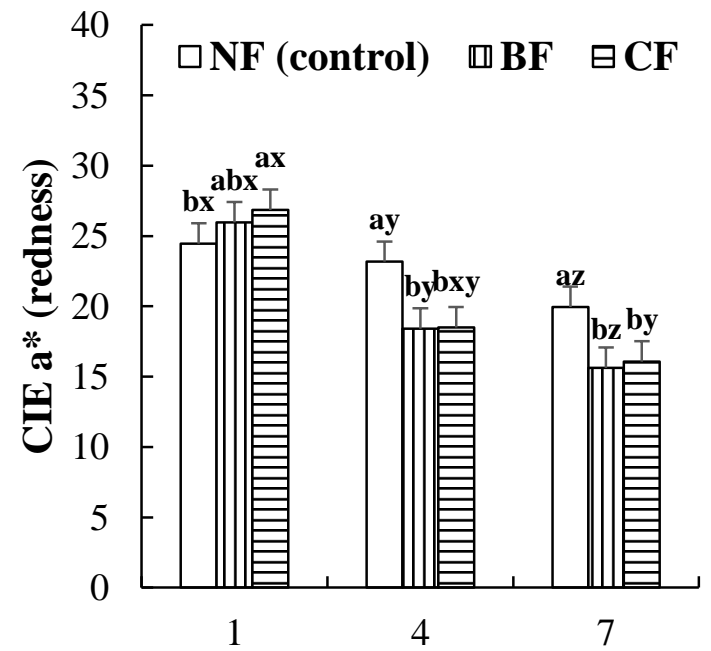

Display period (days) 
(e) Aging effect on yellowness (SEM: 1.07) 1.31)

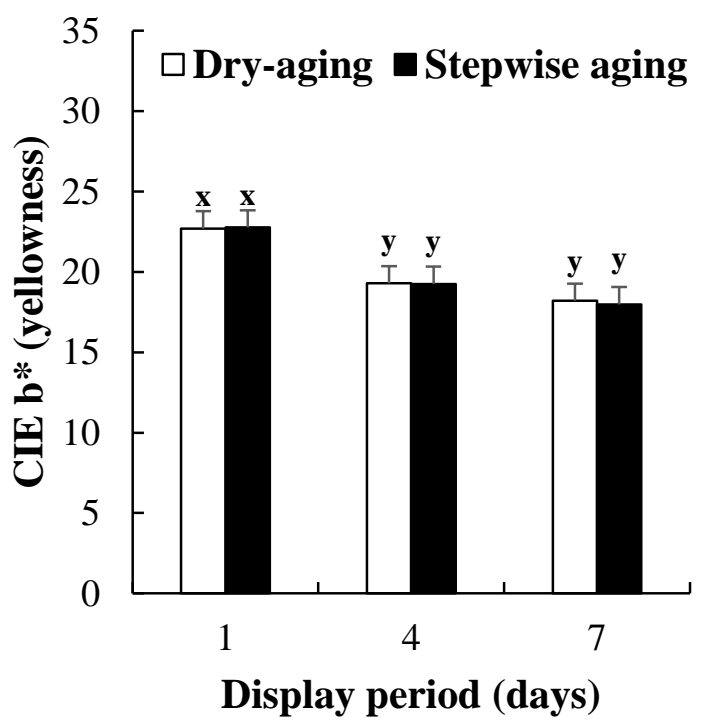

(g) Aging effect on hue angle (SEM: 0.06)

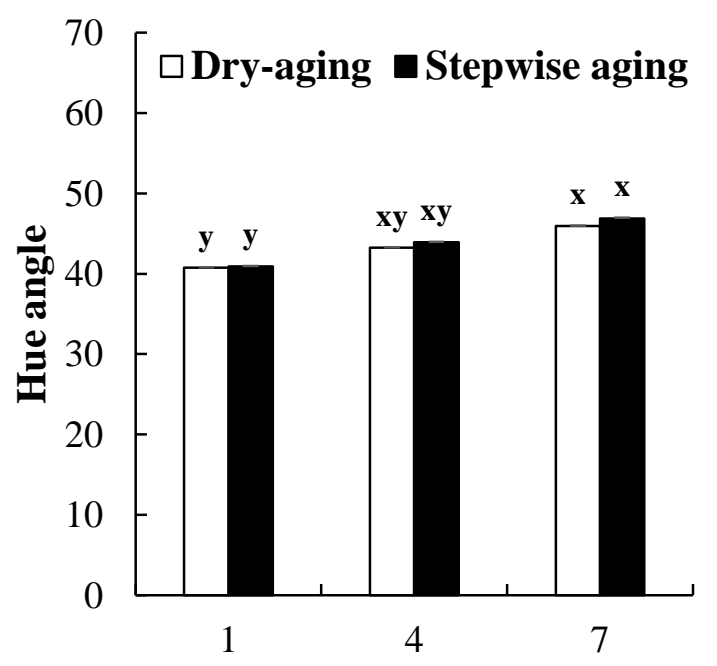

Display period (days) (f) Freezing effect on yellowness (SEM:

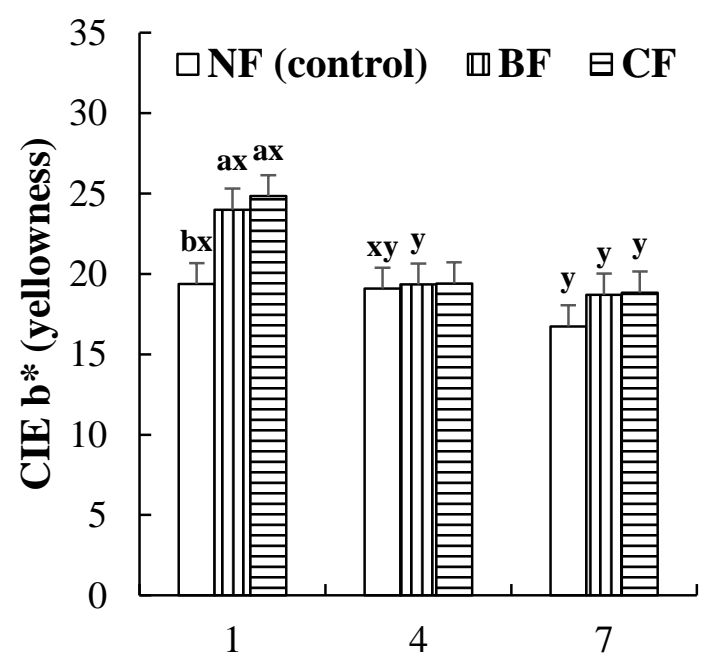

Display period (days)

(h) Freezing effect on hue angle (SEM: 0.07)

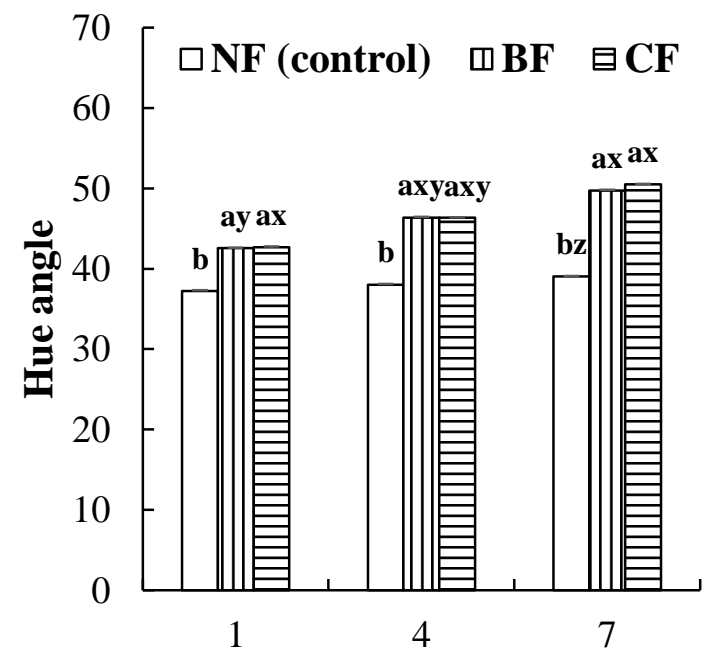

Display period (days)

Fig. 3. Effects of stepwise dry/wet-aging and freezing method on color stability of beef loins during 7 days of retail display. Dry-aging, carcass dry-aging for 17 days; stepwise aging, carcass dry-aging for 10 days and further wet-aging for 7 days. NF, never-frozen; BF, blast-frozen; CF, cryogenic-frozen. SEM: Standard errors of the mean. a,b Different letters between aging/freezing methods within each display period are significantly 
different $(P<0.05)$. x,y Different letters between display periods within each aging/freezing method are significantly different $(\mathrm{P}<0.05)$. 